\title{
Ethical Issues Associated with Mentally III Patient Care
}

\author{
Mustafa Levent Özgönül1 ${ }^{1}$, Kerime BADEMLİ ${ }^{2}$ \\ ${ }^{1}$ Akdeniz University, Faculty of Medicine, Medical History and Ethics Department, Antalya, Turkey \\ Akdeniz University, Faculty of Nursing, Psychiatric Nursing Department, Antalya, Turkey
}

\section{Objectives}

To define possible ethical problems experienced by caregivers in mentally ill patient care

\section{Background}

Caregivers of patients with mental illness experience various difficulties at all stages of the illness and often have to struggle with difficulties alone. In this process, they have to decide on difficult subjects such as hospitalization, compliance with medication, decision on mandatory treatment, decision of involuntary hospitalization. They may experience ethical problems in the subjects such as compulsory treatment, involuntary hospitalization and forced medication.

\section{Methods}

In order to determine the ethical problems experienced by the caregivers of patients with mental illness, a search has been carried out in Google Scholar and Pubmed databases. Screening was carried out with the keywords "caregiver", "ethical dilemmas", "ethical issues", "ethical issues mental illness".

\section{Results}

The caregivers of the patient with mental illness are confronted with the dilemma of disclosure or hiding the sick individual's disease. Caregivers have a dilemma about taking care of the patient and taking decisions on behalf of the patient. Caregivers are experiencing difficulties in deciding on compulsory treatment, decision of involuntary admission, and forced medication.

\section{Conclusions}

The caregivers of patient with mental illness may experience ethical problems in all stages of the caregiving process. It is important for health professionals to identify the situations that cause ethical problems for the caregivers of patients with mental illness. 